\title{
Knowledge and Attitude of Lactating Mothers towards Infant oral health care in Udaipur
}

\author{
Dr. Subha Dogra ${ }^{1}$, Dr. Ruchi Arora ${ }^{2}$, Dr. Deepak P. Bhayya ${ }^{3}$, \\ Dr. Dashmesh Thakur ${ }^{4}$ \\ ${ }^{l}$ (Department of Pedodontics and Preventive Dentistry / RUHS. INDIA) \\ ${ }^{2}$ (Department of Pedodontics and Preventive Dentistry / RUHS. INDIA) \\ ${ }^{3}$ (Department of Pedodontics and Preventive Dentistry / PAHER. INDIA) \\ ${ }^{4}$ (Department of Orthodontics / LMNU. INDIA)
}

\begin{abstract}
Good oral health is an integral component of good health. Infant oral health (IOH) is the foundation upon which preventive education and dental care must be built to enhance the opportunity for lifetime free of preventable oral diseases. Researches show that mothers play an important role in the decision making processes regarding health care for their children. Identifying the indispensible role of mothers about health care for their children it becomes mandatory to assess the knowledge and attitudes regarding infant oral health and educating them as they are the primary care givers. A cross-sectional survey was undertaken among 400 lactating mothers post partum admitted in various government and private hospitals of Udaipur city after obtaining ethical clearance from the concerned authorities. Of the 400 subjects surveyed, included 200 rural mothers from the nearby villages of Udaipur city and 200 urban mothers from Udaipur city. The responses were assessed based on the recommendations of American of Paediatric Dentistry (AAPD).Based on the results of this study it was found that knowledge of mothers was inadequate on IOH care, urban mothers had a comparatively poorer knowledge than rural. There is a need to increase the knowledge of mothers, especially in the urban sector through effective strategies.
\end{abstract}

Keywords: Caries, infant oral health, lactating mothers, pacifiers, teething, weaning.

\section{Introduction}

Good oral health is an integral component of good health. Good oral health includes more than just having healthy teeth; many children have inadequate oral and general health because of active and uncontrolled dental caries [1]. Oral diseases especially dental caries is complicated, multifactorial, transmissible, infectious disease and it often begins to develop during infancy. It is 5 times more common than asthma and 7 times more common than hay fever in children [2,3].

The American Academy of Pediatric Dentistry recommends that all children see a dentist by the age of 12 months [4]. While the American Academy of Pediatrics recommends that children at "caries risk" see a dentist by the age of 12 months [5]. At 12 months, it is considered appropriate to briefly reassess the caries risk of the child and mother and determine if variables have changed. Early childhood caries is the most common chronic disease in young children and may develop as soon as teeth erupt [6].Despite its high prevalence, early childhood caries is a preventable disease. Family physicians caring for both pregnant mothers and infants are uniquely situated to provide early risk assessment, prevention, detection and referral.

Infant oral health $(\mathrm{IOH})$ is the foundation upon which preventive education and dental care must be built to enhance the opportunity for lifetime free of preventable oral diseases [7]. The preventive process must begin early in infancy during the infant's first year to ensure a successful outcome. The purpose of an infant oral health program is to improve access to care, to provide counseling and anticipatory guidance for children aged 6 months to 5 years [8].

Researches show that mothers play an important role in the decision making processes regarding health care for their children [9]. Identifying the indispensible role of mothers about health care for their children it becomes mandatory to assess the knowledge and attitudes regarding infant oral health and educating them as they are the primary care givers.

\section{Aims \& Objectives}

1. To evaluate the knowledge and attitude of lactating mothers on infant oral health.

2. To compare and evaluate the knowledge of urban versus rural lactating mothers.

3. To impart knowledge to lactating mothers on early risk assessment, prevention and detection regarding infant oral health. 


\section{Materials And Methods}

A cross-sectional survey was undertaken among 400 lactating mothers post-partum admitted in various government and private hospitals of Udaipur city after obtaining ethical clearance from the concerned authorities. Of the 400 subjects surveyed, included 200 rural mothers from the nearby villages of Udaipur city and 200 urban mothers from Udaipur city.

A multiple choice questionnaire consisting 18 questions was developed which was divided into two parts- first part consisted of general information and the second part consisted of the questions. The questions were mostly on knowledge regarding infant's oral health. The questionnaire was not pretested and the data was directly collected from each group. The responses were assessed based on the recommendations of American of Paediatric Dentistry (AAPD). For the convenience of the subjects, the questionnaire was printed both in Hindi as well as English.

\section{Results And Discussion}

The results were assessed using chi square and paired $t$ test to compare the association between the groups. Table 1 and Graph 1 show the total knowledge of all subjects on the 18 questions put up in the questionnaire. Graph 2 shows a comparative evaluation between the knowledge of rural versus urban mothers. The knowledge of total number of subjects was found averagely adequate, but surprisingly, the overall knowledge of urban mothers was found significantly less than the rural mothers. The data analysed for mean of total 400 mothers and the results obtained have been discussed as follows.

The WHO recommended infants be fed exclusively on breast milk until six months of age [10]. Although breast feeding provides significant health benefits for infants and mothers, 53\% mothers agreed that prolonged or nocturnal breast feeding should be discouraged after the first primary tooth erupts. Bottle fed infants should not be put to sleep with the bottle.

AAPD recommends that the child be seen within six months of eruption of first primary tooth and no later than 12 months of age [7]. Traditionally the developmental age for initial dental visit was thought to be 3 years. The rationale for this was children are more manageable at this age and the treatment will be more efficient, but early interventions are needed to educate parents on oral hygiene, prevention of dental injuries and ECC [8], hence age one dental visit is recommended. $62 \%$ of mothers agreed that it was essential to visit the dentist before 1 year of age whereas $49 \%$ were aware that the first tooth in child's mouth appears at around 6 months of age.

The use of pacifiers, sweetened liquid/fruit juice in bottle at night was considered harmful by most mothers $(65 \%)$. Often parents, who are too busy to deal with the crying child, try to quieten the child by using the bottle containing milk or other sweetened drinks as a pacifier. This when given frequently to the child before and during sleep has been seen to cause a devastating pattern of nursing caries.

Weaning is the term referred to the diet introduced to the child as a supplement to human breast milk by the age of 4-6 months [11]. $62 \%$ of mothers were aware of the right time of weaning whereas $57 \%$ agreed that good dietary habits during childhood such as consumption of iron fortified infant cereals, breast milk or infant formula can minimize risk of caries development throughout life.

Teething symptoms include fussiness, increased sucking behavior, and loose stools. Increased drooling is common at this age but not necessarily associated with teething. Temperatures higher than $38.1^{\circ} \mathrm{C}\left(100.6^{\circ} \mathrm{F}\right)$ are not associated with teething and should be evaluated for other causes [12]. In spite of most of the mothers (93\%) being aware of the symptoms associated with teething, only $22 \%$ were aware that demand feeding should be stopped when the first tooth erupts and $76 \%$ agreed that it is important to clean an infant's mouth after every feed even before teeth have erupted.

Mutans streptococci typically originate in the mother [13] and are transmitted to the child via saliva contact. The earlier colonization occurs, the greater the risk of caries [14]. Elevated maternal levels of mutans streptococci, due to active or untreated caries and frequent sugar consumption, increase the risk of transmission [15]. A consistently fair knowledge (68\%) was found regarding feeding practices such as pre- chewing children's food which may help in transfer of bacteria causing caries. Educating parents on sharing foods and utensils can help prevent early colonization of oral flora in infants [7].

Optimal exposure to fluoride is important to all dentate infants and children [7]. The use of fluoride for prevention and control of caries is documented to be both safe and effective. Though Udaipur city being in the Fluoride belt, a consistently weak knowledge (45\%) regarding fluoride role in caries prevention was observed. Though, more of rural mothers were able to correctly point out a clear relation between excess fluoride in drinking water and tooth discolouration. This maybe because rural parents surveyed in the study belonged to endemic fluoridated areas. Similar results were seen in a study conducted by Shivprakash PK et al[16].

Most of the subjects (65\%) knew that frequent exposure to sweetened liquids, use of pacifiers and any liquid other than plain water in the bottle at night could cause ECC. However, only $40 \%$ subjects related extended use of sugared medicines as a reason to causing caries. 
Tooth decay remains a substantial problem in young children and is made worse by existing barriers that prevent them from obtaining dental care. The majority of pregnant women get no instructions during pregnancy regarding oral health, even though this is a phase of increased acceptance of instructions that should be used as opportunity to introduce preventive programs [17]. Only $45 \%$ mothers were aware of antenatal counselling whereas $78 \%$ agreed that there is still insufficient knowledge regarding IOH care amongst general population. Also, 59\% knew of a Pedodontist in their locality.

$78 \%$ mothers agreed that habits such as thumb sucking during childhood can lead to several dental problems in future.

Prenatal education is the key to dental care of the infant because mothers should serve as models for their children and much more likely to be successful in an environment where the mother is already a successful patient. The results of this study showed an average knowledge of mothers on $\mathrm{IOH}$, and more surprisingly rural mothers showed comparatively better knowledge. Studies of same design need to be conducted on larger samples and on different sectors of population and groups so as to evaluate which strategies will be effective and efficient in bringing about a behaviour change amongst new parents.

\section{Figures And Tables \\ Table 1.}

Percentage of correct responses given by rural and urban mothers to various aspects of infant oral health

\begin{tabular}{|c|c|}
\hline Questions & $(\%)$ \\
\hline 1. Frequent and prolonged breast feeding can cause tooth decay & 53 \\
\hline 2. Cleaning child's mouth after-before tooth eruption is important & 76 \\
\hline 3. Right age of weaning & 62 \\
\hline 4. First tooth appears at what age & 49 \\
\hline 5. Demand feeding should be stopped after eruption of first tooth erupts & 22 \\
\hline 6. Feeding the child with sweetened liquids/fruit juices may help cause ECC & 65 \\
\hline 7. Teething may be associated with itching of gums, fever, diarrhoea, convulsions & 93 \\
\hline 8. Use of sweetened pacifiers may facilitate early childhood caries & 65 \\
\hline 9. Fluoride in water is responsible for preventing dental caries & 45 \\
\hline 10. The bacteria causing dental caries are transmissible from mother to infant & 68 \\
\hline 11. Number of teeth in child's dentition -20 & 43 \\
\hline 12. Good dietary habits - can minimize risk of caries development throughout life & 57 \\
\hline 13. Habits during childhood such as thumb sucking may cause several dental problems & 78 \\
\hline 14. Extended use of sugared medicines such as cough syrups may help cause caries & 40 \\
\hline 15. Antenatal counselling regarding $\mathrm{IOH}$ is beneficial for parents & 45 \\
\hline 16. There is still insufficient knowledge regarding $\mathrm{IOH}$ & 78 \\
\hline 17. It is important to visit dentist before 1 year of age & 62 \\
\hline 18. Do you know of any Pedodontist in your locality & 59 \\
\hline
\end{tabular}

Graph 1.

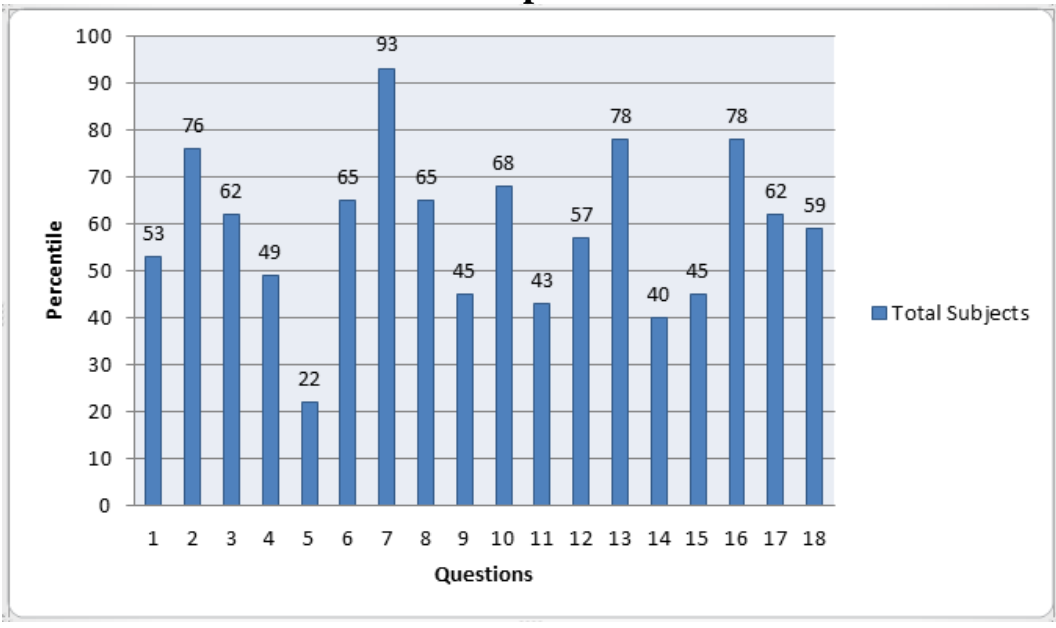




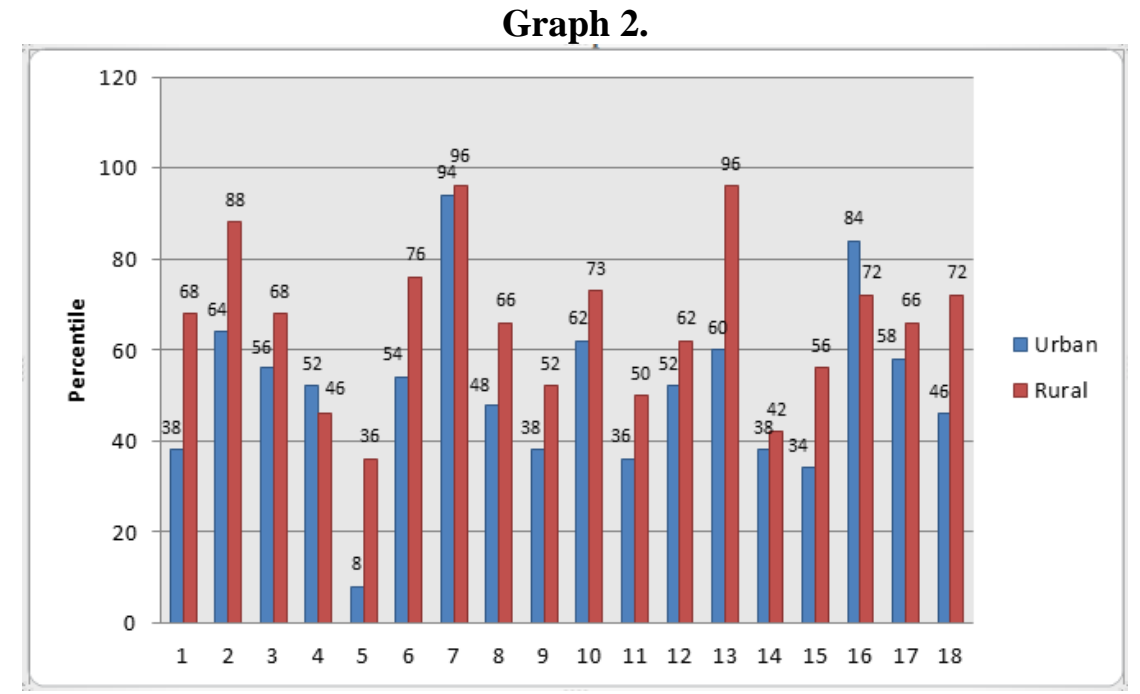

\section{Conclusions}

Based on the results of this study the following conclusions were arrived at:

1. Knowledge of mothers was found inadequate on $\mathrm{IOH}$ care.

2. Urban mothers had a comparatively poorer knowledge than rural.

3. There is a need to increase the knowledge of mothers, especially in the urban sector through effective strategies.

The physician needs to improve and impart IOH counselling; provide anticipatory guidance to parents; and serve as a guide in developing positive dental attitudes. Parents are decision makers in matters of children health and health care, thus they play an important role in achieving the best oral health outcomes for their children. Preventive dental care should start early in infancy, during the first year of child's life to ensure successful outcomes.

\section{References}

[1]. McDonald RE, Avery DR, Dean JA. Dentistry for the child and adolescent $8^{\text {th }}$ ed. Mosby;2004.

[2]. Anticipatory guidance in infant oral health : Rationale and recommendations.Am Fam Physician. 2000; 61 : 115-20, 123- 4.

[3]. Implementing an infant oral program. Journal of the California dental association. 2002; 30(10):752-61.

[4]. Policy on the dental home. In: American Academy of Pediatric Dentistry. Oral health policies. Pediatr Dent. 2002;24(7 suppl): $10-42$.

[5]. Hale KJ. American Academy of Pediatrics Section on Pediatric Dentistry. Oral health risk assessment timing and establishment of the dental home. Pediatrics. 2003;111(5 pt 1):1113-6.

[6]. Douglass JM, Douglass AB, Silk HG. A Practical Guide to Infant Oral Health. Am Fam Physician.2004 Dec 1:70(11):2113-2120.

[7]. American Academy of Paediatric Dentistry. Clinical Guidelines on infant oral health care. Paediatr Dent. 2004;26:67-70.

[8]. Sanchez OM, Childers NK, Fox L, Bradley E. Physicians' views on pediatric preventive dental Care. Pediatr Dent.1997;19:377-83.

[9]. Gross GJ, Howard M. Mothers' decision-making processes regarding health care for their children. Public Health Nurs. 2001;18(3):157-68.

[10]. World Health Organization. The optimal duration of exclusive breastfeeding. A systematic review. Geneva, Switzerland: World Health Organization;2001.

[11]. Kleigman RM, Behrman RE, Jenson HB, Stanton BF. Nelson Texbook of paediatrics $18^{\text {th }}$ ed. Saunders;2007.

[12]. Wake M, Hesketh K, Lucas J. Teething and tooth eruption in infants: a cohort study. Pediatrics. 2000;106:1374-9.

[13]. Li Y, Wang W, Caufield PW. The fidelity of mutans streptococci transmission and caries status correlate with breast-feeding experience among Chinese families. Caries Res. 2000;34:123-32.

[14]. Kohler B, Andreen I, Jonsson B. The earlier the colonization by mutans streptococci, the higher the caries prevalence at 4 years of age. Oral Microbiol Immunol. 1988;3:14-7.

[15]. Kohler B, Bratthall D. Intrafamilial levels of Streptococcus mutans and some aspects of the bacterial transmission. Scand J Dent Res. 1978;86:35-42.

[16]. Shivaprakash PK, Elango I, Baweja DK, Noorani HH. The state of infant healthcare knowledge and awareness: Disparity among parents and healthcare professionals.J Indian Soc Pedod Prev Dent. 2009;27(1):39-43.

[17]. Kumari NR, Sheela S, Sarada PN. Knowledge and attitude on infant oral health amongst graduating students in Kerala. J Indian Soc Pedod Prev Dent 2006;24:173-76. 